\title{
T-Cell Depletion Therapy
}

National Cancer Institute

\section{Source}

National Cancer Institute. T-Cell Depletion Therapy. NCI Thesaurus. Code C15699.

Treatment to destroy $T$ cells, which play an important role in the immune response.

Elimination of T cells from a bone marrow graft or peripheral blood stem cell graft from a donor may reduce the chance of an immune reaction against the recipient's tissues. 